\title{
EDUCACIÓN Y DESARROLLO HUMANO. UNA PROPUESTA DE EDUCACIÓN HUMANISTA PARA LATINOAMÉRICA
}

\author{
Liliana Beatriz Irizar ${ }^{1}$ \\ Universidad Sergio Arboleda- Colombia \\ liliana.irizar@gmail.com \\ Javier Nicolás González Camargo ${ }^{2}$ \\ Universidad Sergio Arboleda- Colombia \\ Camilo Noguera Pardo ${ }^{3}$ \\ Universidad Sergio Arboleda- Colombia
}

Recepción: 11/05/2010

Evaluación: 5/07/2010

Aceptación: 18/09/2010

Artículo de Revisión

\section{RESUMEN}

El objetivo de este trabajo consiste en analizar el vínculo entre educación y desarrollo partiendo de una visión crítica del enfoque antropológico bajo el cual se ha venido

\footnotetext{
1 Abogada por la Pontificia Universidad Católica Argentina Santa María de los Buenos Aires y Doctora en filosofía por la Universidad de Barcelona. Desde enero de 2004 dirige el grupo de investigación Lumen de las Escuelas de Filosofía y Derecho - Línea de investigación: Filosofía del Derecho y Filosofía Política - Universidad Sergio Arboleda. Proyectos a su cargo: desde 2004 se está desarrollando: Humanismo cívico: un nuevo modo de pensar y comportarse. Acerca de la propuesta filosófico-política de Alejandro Llano. Desde enero 2008 se desarrolla: el Proyecto Dewan en español. Un proyecto de investigación que se propone analizar, profundizar y difundir el pensamiento del profesor canadiense Lawrence Dewan en el mundo de habla hispana.

2 Licenciado en Filosofía y Humanidades de la Universidad Sergio Arboleda, en Noviembre de 2010. Investigador Auxiliar del Grupo de Investigación Lumen de la Escuela de Filosofía y Humanidades de la Universidad Sergio Arboleda, Bogotá, y Docente Titular de Filosofía del Instituto Filosófico Teológico Santo Tomás de Aquino, Tocancipá. 3 Abogado por la Universidad Sergio Arboleda y candidato a Magister en la Maestría en Docencia e Investigación de la Universidad Sergio Arboleda. Es profesor catedrático de Gramática en la Escuela de Filosofía y Humanidades de la Universidad Sergio Arboleda.
} 
orientando la educación en Latinoamérica. Como alternativa al actual modo de enfocar dicha relación, se propone una visión humanista de la educación que reconoce como premisa fundamental la índole espiritual del ser humano, la comprensión de la libertad como liberación de sí mismo y la capacidad de la persona para abordar su propia vida y ayudar a orientar la de los demás según un modo de pensar y de vivir profundamente humano gracias al cultivo de las virtudes intelectuales yéticas. El humanismo cívico sirve como trasfondo filosófico-político de esta propuesta humanista de educación.

Palabras clave: Naturaleza Humana, Alma Espiritual, Educación, Desarrollo, Libertad, Arte De Vivir Y Humanismo Cívico.

\title{
EDUCATIONAND HUMAN DEVELOPMENT. A HUMAN EDUCATIONAL PURPOSE IN LATINAMERICA
}

\author{
Liliana Beatriz Irizar \\ Universidad Sergio Arboleda- Colombia \\ liliana.irizar@gmail.com \\ Javier Nicolás González Camargo \\ Universidad Sergio Arboleda- Colombia \\ Camilo Noguera Pardo \\ Universidad Sergio Arboleda- Colombia
}

\begin{abstract}
The aim of this paper is to analyze the link between education and development starting from a critical vision of the anthropological approach which has been guiding education in Latin-America. As an alternative of the current way of approaching that relationship, we propose a humanistic vision of education which recognizes as primary premise the spiritual condition of human being, the understanding of freedom as liberation of oneself and human people's capacity to leader their own life and help others to direct their lives according to a wise way of thinking and living thank to intellectual and moral virtues. Civic Humanism is the philosophical-political background of this humanistic education proposal.
\end{abstract}

Key words: Human Nature, Spiritual Soul, Education, Development, Freedom, Art of Living and Civic Humanism. 


\section{INTRODUCCIÓN}

"Me encuentro hundido y siento la necesidad de escribirles. Mi generación nació en la violencia; en el mundo los niños mueren de hambre y de sed, por todas partes sufren violencias de todo tipo. Ya me he acostumbrado a verlo todo sin emocionarme, a desinteresarme de todo y de todos. Asumo de antemano todas mis culpas futuras, pero la generación de mi padre tiene que asumir las culpas de lo que yo pienso y de eso en lo que me he convertido. Los jóvenes constituimos una sociedad aparte. Que a un niño le quiten los caramelos como que los hijos maten a sus propios padres, produce en nosotros las mismas emociones... Tenemos que desfogarnos contra alguien: contra el mendigo, el borracho, la persona anciana, da igual, lo importante es que sea más débil que nosotros, y si no lo es, recurro a las armas. Porque estamos cargados con la violencia que vemos en la televisión y por la calle... Soy una bomba sin explotar, mi generación es un conjunto de bombas sin explotar; basta un clic y tanto yo como los otros estamos dispuestos a matar por nada. No nos pregunten por qué no creemos en el amor, en una relación de verdad y para siempre, por qué nos drogamos, por qué nos emborrachamos, por qué somos violentos, por qué nos inventamos nuestro propio lenguaje. Pregúntense, más bien, dónde se han equivocado ustedes. Si la respuesta es un conjunto de excusas o un intento de descargar la responsabilidad de ustedes, entonces, son ustedes los primeros que tienen que madurar...."

Carta de un joven al director de una revista.

Se podría decir que existe un consenso universal acerca de que la educación es uno de los factores que contribuye de modo decisivo al desarrollo de los individuos y de los pueblos.

Uniéndose a dicho consenso, el presente ensayo tiene como objetivo principal indagar sobre los presupuestos antropológicos y éticos que mejor pueden contribuir al desarrollo humano auténtico mostrando, asimismo, que a través de este último es como la libertad individual y social se conquista, crece y se despliega en diversas expresiones culturales y políticas que favorecen, a su vez, el desarrollo de la persona. Este artículo se enmarca en la relación entre educación y política, y aborda dicha relación desde una perspectiva profundamente filosófica.

Si bien nos basaremos en principios filosóficos, que son en sí mismos universales, no obstante, nuestra reflexión se dirige especialmente a analizar el vínculo entre educación y desarrollo en Latinoamérica, orientándonos hacia la específica manifestación que el sistema y las tendencias educativas 
latinoamericanas presentan como consecuencia del enfoque antropológico que ellas han asumido, para reevaluar dicho enfoque.

Pasados los años 80, en Latinoamérica ha sido ampliamente promovida la denominada educación personalizada, como también la educación integral. Sin embargo, su relación con el desarrollo ha sido, cuando menos, ambigua. Lo más usual ha sido asumir un personalismo autonomista que no pocas veces pacta con una especie de personalismo igualitarista. En este sentido, muchas veces en Latinoamérica la relación de la educación personalizada e integral y la política, han retomado las banderas de la educación libertaria del tipo Freire o Montessori, generando simbiosis o eclecticismos usualmente inconscientes, pues se pasa por alto que la concepción de educación de estos últimos autores correspondía a un modelo de desarrollo socialista, en su momento incompatible con el modelo personalista de origen cristiano. Tras la caída del bloque socialista, la educación libertaria abandonó un poco su fuerte filiación marxista y se abonó a las tierras del autonomismo kantiano. Poco a poco se sumó la educación en valores, y las propuestas más contemporáneas en torno a los principios del diálogo y del pluralismo, que suelen anclarse en una especie de personalismo hermenéutico, cuyo resultado suele ser el abogar por un diálogo sin condicionar por las categorías de verdadero-falso. Empero, cuando el autonomismo kantiano, la educación en valores, y el personalismo hermenéutico se mezclan indiscriminadamente en el terreno educativo, se acaba por carecer de una fundamentación o definición fuerte, o al menos clara, acerca de lo que es la persona y en qué consiste su auténtico desarrollo y, por consiguiente, se desconocen las vías e instrumentos educativos que conducen eficazmente a él.

En los congresos realizados en Cuba y en Paris sobre "Políticas y Estrategias para la transformación de la Educación Superior en América Latina y el Caribe"4 se analizaron serias falencias de la educación, errores que terminan por imposibilitar toda visión y todo quehacer en torno a una cultura de la educación, de la persona y de la paz. Dentro de las equivocaciones se reconocieron, por ejemplo, trabas referentes a la financiación, deficiencias grandes de cobertura, corrupciones marcadas en los procesos de calidad y acreditación, así como malinterpretaciones del principio de la autonomía universitaria. Ciertamente todos estos desaciertos repetidos que terminan por invadir y dirigir las políticas educativas tienen profundas incidencias en el desarrollo universitario y, por tanto, en la formación personal que permite la mejora social.

\footnotetext{
4 MEMORIAS. (1998): Políticas y Estrategias para la transformación de la Educación Superior en América Latina y el Caribe. UNESCO, ASCUN.
} 
Sin embargo, en dicho diagnóstico se relega el factor que más radicalmente socava a la educación desde su misma base. Se olvida mencionar que la raíz de los problemas allí denunciados, tanto como de otros que no se mencionan, es de tipo antropológico y ético. Se trata de la carencia de un modelo educativo dirigido hacia la persona en toda su integridad, concibiendo y enfocando sus procesos hacia la realidad del individuo, hacia la posibilidad de continuar un mejor modelo de vida, "preparando a sus egresados para que aporten y se vinculen más fácilmente a los procesos transformativos de sus realidades." ${ }^{5}$

Es la educación por la persona y para ella:

Nunca como ahora tiene más validez la tesis del gurú Peter Drucker, cuando afirma que el conocimiento no reside en un libro, un banco de datos, un programa de computación. Estos últimos solo tienen información. El conocimiento siempre está encarnado en una persona, transmitido por una persona, usado o abusado por una persona, por eso el cambio a la sociedad del conocimiento pone al individuo en el centro, así aparecen nuevos retos, nuevos temas, nuevas preguntas sobre el representante de la sociedad del conocimiento, la persona educada. ${ }^{6}$

En cambio, ¿qué tipo de hombre es el que entregan las instituciones educativas luego de un tiempo de estudio?, ¿qué tipo de personalidad es tenida en cuenta en los procesos de formación? Sin ánimo de ser pesimistas, hay que decir que, en términos generales, nuestros sistemas de educación están diseñados para dar, al final del proceso, con un hombre mecánico y poseedor de un saber fragmentado y parcial. Tal como ha observado Ortega y Gasset:

Falta a nuestra época la conciencia de la cultura, esto es, de aquella cosa que en apariencia más la envanece (...) Merced a ello ha multiplicado los médicos, los ingenieros, los abogados, los técnicos, los lectores de periódico $y$, en cambio, ha restado los hombres cultos. Causa última, síntoma definitivo de esta mengua es que padece nuestra época una forma específica de la incultura, precisamente el desconocimiento de aquellas meditaciones en que se aclara el sentido de la cultura, y en consecuencia el sentido de la vida humana: es la incultura del sabio médico, del sabio ingeniero, del sabio jurista, la ignorancia de lo general que padece el sabio de lo especial. ${ }^{7}$

\footnotetext{
5 RAMÍREZ, Luis Alfonso. (1998): Políticas y Estrategias para la transformación de la Educación Superior en América Latina y el Caribe. Discurso de instalación. UNESCO, ASCUN, p. 13.

6 MUÑOZ, Luis Carlos. (1998): Políticas y Estrategias para la transformación de la Educación Superior en América Latina y el Caribe. Discurso de instalación. UNESCO, ASCUN p. 21.

7 ORTEGA Y GASSET, José. (2002): Misión de la Universidad. Madrid, Alianza, p. 94.
} 
¿Dónde queda entonces la educación de la libertad, el cultivo de la virtud, el crecimiento y la formación espiritual y emocional?, ¿qué sucede con el pensamiento auténtico? Sencillamente se ignoran. Estamos ante un fenómeno único en la historia de la educación occidental, pero probablemente más palpable e hiriente en Latinoamérica, es el momento de los doctores con mala ortografía y defectuosa expresión. Saberes universales, como aquellos del lenguaje culto, la geografía o las matemáticas, por no decir la filosofía, las artes en general o la literatura, son campantemente ignorados por muchos que ostentan títulos de magíster o doctores. Hoy, en muchas ocasiones, para saber y tener la cultura que antes se conseguía con un bachillerato o un pregrado, hay que hacer un postgrado. Es decir, vemos un avance en las titulaciones, pero un retroceso en el contenido de los títulos; y esto no obedece ciertamente al progreso del conocimiento hacia el cual va dirigido, en principio, todo el impulso que se le viene dando a la investigación.

De esta manera, “(...) nos encontramos en la fase terminal de una época en la que la mayoría de los movimientos culturales que se detectan presentan una índole inercial," 8 muchas de las tradiciones, y muy claramente en aquellas comunidades que más esfuerzos parecen hacer por preservarlas, se realizan ahora con desconocimiento generalizado de su sentido original, o por lo menos, con su menosprecio, cuando no es con una total oposición cultural e ideológica. Desafortunadamente, dentro del ámbito educativo, muchas de las tradiciones, protocolos, instituciones, símbolos, máximas, y probablemente las más importantes, presentan este carácter desesperado e inercial.

Es preciso rescatar esta primacía de la educación. Ahora bien, con el término "educación" designamos un ámbito mucho más amplio que el de la simple erudición o el de la preparación técnica. Al hablar de educación nos referimos a la formación integral de la persona, formación que abarca no sólo la dimensión intelectiva del ser humano, sino también la afectiva y la espiritual. Por tanto, un indicador clave del grado de educación de un individuo o de una comunidad, es su capacidad de hacer un uso responsable y abierto -relacional- de la libertad.

La educación integral y personal que aquí se propone, parte de las premisas filosóficas en que se sustenta el modelo socio-político denominado humanismo cívico. ${ }^{9}$ El humanismo cívico promueve la participación directa e indirecta de la ciudadanía como motor irreductible e irremplazable de la dinámica política, especialmente la democrática. Es así que el humanismo cívico une

${ }^{8}$ LLANO, Alejandro. (2003): Repensar la universidad. Madrid, EIUNSA, p. 118.

9 LLANO, Alejandro. (1999): Humanismo cívico. Barcelona, Ariel, p. 67. 
armónicamente dos fundamentos que suelen presentarse como antagónicos. Por un lado, lo mejor de la tradición filosófico-política clásica, es decir, la apuesta por la búsqueda de la convivencia y el entrecruzamiento de las libertades individuales según un criterio de máximos tales como la amistad cívica y el bien común. Por otro lado, las aportaciones más valiosas de la tradición moderna, esto es, la apertura democrática y la consagración de los DDHH.

El humanismo cívico denuncia que el llamado "tecnosistema" (Estado, mercado y medios de comunicación, es decir, los tres componentes estructurales del Estado de bienestar) ha ido desplazando poco a poco a los auténticos protagonistas de la vida social y política. Podemos afirmar que somos extranjeros en nuestra propia tierra: la polis o ciudad- ya no nos pertenece; habitamos, sobrevivimos en ella, pero carecemos de ideales y proyectos que nos liguen a un mismo suelo político. Carecemos asimismo de metas comunes que nos permitan comprendernos a nosotros mismos y crecer unidos, entrelazando nuestros sueños personales en un entramado sólido de fidelidades y compromisos comunitarios. Esta denuncia es sostenida hoy, en términos más o menos similares, por diferentes pensadores que pueden ser enrolados en la corriente de pensamiento denominada humanismo cívico. Básicamente, dichos autores coinciden todos en alzar su voz contra la lógica del poder puro y contra el menosprecio de la dignidad de la persona y de su libertad esencial que tal lógica implica.

Antes de continuar con nuestra exposición, conviene tener presente qué entendemos aquí por desarrollo humano. Al hablar de desarrollo humano hacemos referencia a la acumulativa adquisición de valores cada vez más altos, más exigentes, más humanos y más espirituales, de que es capaz una sociedad y sus instituciones. Este desarrollo incluye, como es natural, el que la comunidad, así desarrollada, posea la capacidad de promover y transmitir dichos valores entre sus integrantes. El acopio vivencial de valores se hace posible únicamente por la consecuente encarnación de los mismos en prácticas y virtudes ${ }^{10}$ que devienen en costumbres sociales. Éstas, a su vez, permiten a una comunidad enfrentar con éxito, es decir, sin necesidad de sacrificar violentamente la integridad de las personas, los retos, conflictos y dificultades que se le presenten. Cabe advertir, asimismo, que uno de los signos del desarrollo auténtico consiste en el hecho de que las libertades individuales se orientan gradualmente hacia la participación solidaria en proyectos comunes. En suma, se podría afirmar que el auténtico desarrollo, al igual que el bien, es difusivo, multiplicador, porque influyendo

\footnotetext{
${ }^{10}$ MACINTYRE, Alasdair. (1999): Tras la virtud. Trad. A. Valcárcel. Barcelona. Editorial Crítica, pp. 226-237.
} 
positivamente en cada individuo, es capaz de expandirse vigorosamente en el todo social. Por eso, tal como advierte Alejandro Llano: "Lo que precisamos es energía moral e intelectual, para romper el cerco del conformismo y activar focos que irradien altura de miras y capacidad de innovación. Porque la dinámica de la vida científica y cultural responde a otros parámetros diversos a los del despliegue de la materia. Una palabra de verdad, un propósito de solidaridad, un vislumbre de belleza, poseen una fuerza que puede llegar a ser incontenible si aciertan a pulsar esa nota esencial que encuentra ecos insospechados en las aspiraciones profundas de tantos hombres." 11

Pues bien, en el "imperio sistémico" rige, efectivamente, la hegemonía de lo cuantitativo, con la consiguiente marginación de lo humano, es decir, de las personas, únicas y legítimas gestoras del dinamismo social y político. Esta renuncia a lo humano y a lo cualitativo, como elemento que configura el sentido y la condición del crecimiento personal y comunitario, se traduce de hecho, en el campo político, en un avasallamiento del aparato estatal que tiene como contrapartida la pasividad y la inercia de una ciudadanía que hace tiempo ha dejado de reconocerse a sí misma como la legítima hacedora de la vida y del destino de la polis. ${ }^{12}$ Bajo este espectro sociopolítico, y teniendo como objetivo despertar al ciudadano del sueño del individualismo y la apatía cívica, al humanismo cívico le interesa especialmente la educación.

La convicción de que sólo mediante una firme y decidida educación se alcanza el pleno desarrollo humano, y se abren las puertas del progreso para una sociedad, es esencial a la propuesta de la tradición cívica. Pero la propuesta no se limita a anhelar la educación, o a solicitarla. El humanismo cívico es rotundo en afirmar los principios bajo los cuales debe ser considerada dicha educación, con lo que busca generar la coherencia necesaria entre los postulados antropológicos de los que parte, las conclusiones educativas a las que llega, y las consecuencias políticas que anhela. Considera que la educación es algo muy importante como para dejarlo a la vaga interpretación, la simple buena intención, el azar, o las técnicas pedagógicas preestablecidas. En la educación el humanismo cívico alcanza su operatividad, y se salva de los riesgos de utopismo, tan poco deseables para cualquier propuesta política seria en estos tiempos.

\footnotetext{
${ }^{11}$ LLANO, Alejandro. (1985): El futuro de la libertad. Pamplona. EUNSA, p.12.

12 IRIZAR, Liliana. (2006): Preámbulos de la esperanza. Reflexiones en torno al humanismo cívico de Alejandro Llano. Bogotá, Fondo de Publicaciones de la Universidad Sergio Arboleda, p. 5.
} 


\section{Educar según un modelo antropológico no materialista}

Educar es, ante todo, ayudar a un ser humano a que alcance su plenitud como persona. Para eso hace falta llegar a la mente, pero también, y sobre todo, al corazón del niño o del joven. La auténtica educación es formación, es decir, un arte por el cual se da forma o se configura la inteligencia mediante la verdad y se modela la afectividad de acuerdo con el bien. De acuerdo con esta definición, queda claro que es posible, e incluso necesaria, la auto-educación; tarea, por otra parte, imprescindible en quien aspire a cooperar en la formación de otros seres humanos. Formar a un ser humano implica, entonces, que el formador conoce esta premisa ineludible: sabe quién es el ser humano. Es esta una premisa esencial para el humanismo cívico, premisa a través de la cual se hace eco de la perspectiva antropológica propia de los antiguos. Muy concretamente, de Aristóteles y Tomás de Aquino.

Aristóteles hacia el final de la Ética a Nicómaco nos recuerda la grandeza de nuestro ser personal cuando afirma que "...no hemos de seguir los consejos de algunos que dicen que, siendo hombres, debemos pensar sólo humanamente $\mathrm{y}$, siendo mortales, ocuparnos sólo de las cosas mortales, sino que debemos, en la medida de lo posible inmortalizarnos y hacer todo esfuerzo para vivir de acuerdo con lo más excelente que hay en nosotros." 13 Aristóteles alude de ese modo al carácter racional o espiritual del alma humana indicando que se trata de una dimensión, la espiritual, que no podemos evadir si queremos alcanzar nuestro fin o telos propio, esto es, nuestra propia realización como seres humanos. En este sentido, conviene recordar aquí la centralidad que ocupa la noción de naturaleza en una antropología, como la aristotélica, la cual, sin menospreciar el valor del cuerpo, rescata la preeminencia del espíritu sobre la materia.

Al hablar de naturaleza, tanto Aristóteles como Tomás de Aquino, en medio de toda una tradición clásica del discurrir filosófico, apuntan a la comprensión metafísica de la misma. Bajo este aspecto, la naturaleza es la esencia o principio ontológico que define intrínsecamente lo que cada ser es en sí mismo; ${ }^{14}$ de ahí la conocida definición de esencia o naturaleza ${ }^{15}$ como aquello que hace que algo sea (especificamente) lo que es.

Es importante remarcar que para la filosofía aristotélico-tomista la naturaleza, entendida como algo dotado de fines naturales inmanentes, abarca

\footnotetext{
13 ARISTÓTELES. (Trad. 1993): Ética Nicomaquea. Madrid, Gredos, X, 8.

14 ARISTÓTELES. (Trad. 1994): Metafísica. Madrid, Gredos, 1029b10-15.

15 Sobre los diferentes nombres de la esencia véase DE AQUINO, Tomás. (2001): El ente y la esencia., en Opúsculos y cuestiones selectas. Madrid, BAC, c.1.
} 
asimismo a la naturaleza humana. Por esta razón, "También los fines humanos son naturales, la doctrina del alma humana es una parte de la 'Física."16 Dicha naturaleza es al mismo tiempo principio y fin: fuente de la operatividad de un ser y meta ${ }^{17}$ hacia la cual debe dirigirse su despliegue existencial. Justamente, esta doble caracterización de la naturaleza como principio y fin es lo que la habilita para ser de suyo normativa: ella es parámetro, regla que permite valorar ("medir") qué operaciones son o no naturales para un determinado ser. Se comprende, así, que la naturaleza teleológica sea también límite. Un límite que no es una simple restricción, sino la demarcación positiva de lo que constituyen auténticos bienes para la persona. Se trata, tal como señala Spaemann, de "un límite sensato, es, decir, un telos, un límite cuyo respeto nos lleve a la realización de lo que propiamente somos como seres humanos." 18

Somos conscientes de la novedad de este lenguaje, ciertamente inusual, debido a que, desde hace siglos, ${ }^{19}$ hemos asumido que los únicos fines que existen son los objetivos o metas que se fija el ser humano y que, por tanto, son consecuencia de su libertad.

Sin embargo, lo que proponemos en este escrito es la necesidad de rehabilitar la comprensión de la naturaleza en los términos aquí planteados. Para educar la persona es preciso conocer tan profundamente como sea posible quién es, es decir, se necesita contar con un conocimiento riguroso y amplio acerca de todas las dimensiones que integran su ser personal. Por consiguiente, es ineludible partir de un estudio fundamental dirigido a la comprensión de la naturaleza humana y de su telos.

Una vez asumida la teleología presente en toda esencia o naturaleza, también en la humana, estamos en condiciones de vernos a nosotros mismos no meramente como sujetos con capacidad de elección, sino como dotados también de una inclinación natural, ${ }^{20}$ puesto que de toda forma se sigue una

\footnotetext{
16 SPAEMANN, Robert. (1994): Ensayos filosóficos. Madrid, Ediciones Cristiandad, p.52.

17 ARISTÓTELES. (Trad. 1995): Física. Madrid, Gredos, II, C. 8, 199a5-10.

18 SPAEMANN. (1994): óp., cit, p. 64. Tengamos presente, con todo, que esta nota de la normatividad, en rigor, únicamente es aplicable a la naturaleza humana, ya que sólo el ser humano, en virtud de su racionalidad, es capaz de conocer la propia naturaleza en cuanto tal y, a partir de esta comprensión, aceptarla, o no, como ley y patrón de conducta (cf. GONZÁLEZ GONZÁLEZ, Ana Marta. (1999): Naturaleza y dignidad. Un estudio desde Robert Spaemann. Pamplona, EUNSA, pp. 115-116.

19 SPAEMANN, Robert. (1994): Ensayos filosóficos. Madrid, Ediciones Cristiandad, p.48 y ss.

${ }^{20}$ DEWAN, L., O.P. (2008): Wisdom, Law and Virtue, Essays in Thomistic Ethics. New York, Fordham University Press, p. 17. (Las traducciones de la obra del profesor Dewan extraídas directamente del texto original, son de L. Irizar).
} 
inclinación. Ahora bien, la tendencia natural, en el caso del ser humano, es la que corresponde a una naturaleza racional o espiritual que, tal como ha enseñado Aristóteles, es en cierto modo infinita, respecto de la naturaleza corpórea. Porque somos en efecto, capaces de conocer "todas las cosas."21 Resulta así claro que como seres dotados de una naturaleza "poseemos un deseo natural proporcionado a dicha capacidad cognoscitiva universal. Esto es entender el ser humano como una naturaleza con un fin natural: alcanzar un estado desarrollado de plenitud natural que rige la concepción de la ética en su integridad." 22

Aristóteles $^{23}$ apelará a su conocido argumento del ergon o función propia del hombre para mostrar que tal fin natural consiste en llevar una vida plenamente racional, es decir, desarrollada al hilo de las virtudes éticas e intelectuales. ${ }^{24}$ Tomás de Aquino, como veremos, ahondará todavía más en el tema de la felicidad humana, pero coincidiendo con el Estagirita en algunos de sus argumentos medulares.

Así, criatura corporal pero poseedora de una naturaleza racional o espiritual, la persona destaca, en todo el universo creado por su inteligencia que le permite abrirse al mundo y, a su vez, traspasar los contornos sensibles del mismo, esto es, trascenderlo. Dicho con otros términos, el principio vital humano goza, por decirlo así, de la "plasticidad" propia de las realidades espirituales lo que le permite revestirse, en cierto sentido, de infinitud. Porque, como enseña Aristóteles, además de ser lo que es en virtud de su naturaleza específica, el alma humana puede llegar a ser intencionalmente todas las cosas y hacer suya la perfección del universo. ${ }^{25}$

Queremos destacar aquí las substanciales implicaciones que supone para la vida personal y social reivindicar este alcance metafísico de la razón, es decir, de su capacidad de abrirse al horizonte ilimitado del ser. La razón humana posee la aptitud natural de captar los componentes no materiales o inteligibles del mundo sensible o físico con el que el ser humano se relaciona de manera constante y directa. Dichos componentes, si bien son imperceptibles a simple vista, no son por eso menos relevantes, sino más. Precisamente, son estos datos intangibles los que permiten descifrar, en último término, el sentido profundo

\footnotetext{
${ }^{21}$ ARISTÓTELES. (Trad. 1978): Acerca del alma. Gredos, III.6, 430b21-25.

22 DEWAN. (2008): óp., cit, p.17.

${ }^{23}$ ARISTÓTELES. (Trad. 1993), óp., cit, p, I.7.

${ }^{24}$ Cf. ARISTÓTELES. (Trad.1993), óp., cit, I.

${ }^{25}$ ARISTÓTELES. (Trad. 1978), óp., cit, III, 6, 430b21-25.
} 
de las realidades tanto humanas como no humanas. Por el contrario, si no se le reconoce a la razón su capacidad metafísica, la pregunta por el sentido último de la propia existencia, el significado del dolor o de la muerte, al quedar fuera del espectro de los intereses y métodos específicos de las ciencias empíricas y de las nuevas tecnologías, permanecen sencillamente sin respuesta, e incluso ni siquiera cabe el espacio para su planteamiento.

De modo que, los procesos educativos, entendidos como instrumento esencial del desarrollo humano, deben asumir y profundizar en esta verdad elemental: el ser humano posee alma, y un alma espiritual. Lo que lo define y distingue de los demás seres es su espíritu, fuente de su capacidad de pensar y de sus elecciones libres. Pensamiento y libertad son las claves de comprensión de un ser que por naturaleza se encuentra inclinado a autotrascenderse y a comunicarse relacionalmente, tanto con las demás personas como con la Verdad que lo trasciende de modo absoluto.

Así, se puede afirmar que existen unos parámetros antropológicos y éticos a la luz de los cuales es preciso evaluar la calidad y el alcance formativo de los programas de educación. Es necesario preguntarse si el estudiante, a través de estos últimos, se hace realmente mejor, más maduro espiritualmente, más responsable en el uso de su libertad y más abierto a los demás.

\section{Un nuevo modo de pensar}

La humanización de la cultura a través de una educación humanista, tal como la concibe y promueve el humanismo cívico, exige el esfuerzo y la creatividad de optar por un modo de racionalidad que supere los ya consabidos y transitados modelos del pensamiento único, es decir, los del racionalismo cientificista. No se trata de abandonar ni de menospreciar las aportaciones propias de las disciplinas estrictamente científicas. Lo que aquí se propone es la invitación a abordar los grandes temas que más afectan al hombre desde una perspectiva sapiencial. Los interrogantes esenciales exigen respuestas esenciales. La experimentación, el cálculo o la sola metodología no ofrecen ni pueden ofrecer todas las respuestas.

Para que la educación pueda hacer frente a los enormes desafíos ofrecidos por los profundos cambios culturales, es necesario un ensanchamiento de nuestra comprensión de la racionalidad. Se trata de superar los límites de la "razón científica" y avanzar con resolución hacia la "razón metafísica" y constatar de ese modo que la inteligencia humana es capaz de explorar y abarcar los aspectos 
de la realidad que van más allá de lo puramente empírico, dando, así, paso a su ejercicio analógico y abierto a toda la realidad.

Conviene tener presente que la pretendida razón "pura" del racionalismo cientificista dominante ha conseguido imponer un modelo antropológico y ético que falsea la realidad del hombre y de la vida social. Ahora bien, el resultado inevitable de tal tergiversación, son el relativismo como ideología que arroja a la libertad humana en el vacío y la oscuridad del sinsentido. Y la violencia como reacción, ante una realidad, la humana, que se presenta como ambigua e indescifrable a la razón positivista y su método insuficiente. La otra cara de la moneda del objetivismo cientificista y de la hipertecnología lo constituye, así, el instintivismo irracional y relativista. ${ }^{26}$

El pensar reflexivo o meditativo, en cambio, se caracteriza por ir a la raíz de las cosas. Este modo de pensar no se propone saber muchas cosas, sino comprender y ahondar en las fundamentales, es decir, en aquellas verdades que ayudan a vivir más auténticamente. Desde Aristóteles sabemos que la sabiduría se ocupa de pocas cosas, pero que son las más importantes. Por eso, el que reflexiona de manera sabia, aunque no conozca acerca de muchos temas, en la vida práctica llega más lejos porque la profundidad alcanzada le da luz para comprender mejor la realidad: la que le envuelve, la suya propia, la de los demás...

El que profundiza en la verdad gana en concentración y evita la dispersión que conlleva el aprendizaje acelerado y superficial de nuevos conocimientos. Alguien ha comparado al hombre característico de la sociedad del conocimiento con el esquiador, asociando al sabio con el agricultor. El esquiador se desliza veloz sobre el suelo cubierto de nieve y no deja casi rastro de su paso. El agricultor, en cambio, sobre todo antiguamente y en algunos lugares aún hoy día, va lentamente detrás de la yunta, metiendo el arado a fondo para remover la tierra y dejando un surco bien marcado detrás de sí. De forma semejante, quien lee mucho, sin apuntar a contenidos esenciales y sin reflexionar, se queda en la superficie. El que asume una actitud sapiencial, es decir, sabiamente reflexiva, penetra en lo que estudia y se prepara para leer en el interior de la realidad, de los acontecimientos y especialmente en el interior de sí mismo. No en vano Tomás de Aquino ha enseñado que inteligir, o entender, significa "leer dentro", entrar con la inteligencia hasta lo más íntimo de la realidad, es decir, hasta su núcleo esencial. ${ }^{27}$

\footnotetext{
${ }^{26}$ LLANO. (1999): óp., cit, p. 57.

${ }^{27}$ DE AQUINO, Tomás. (Trad. 1950-1964): Suma teológica. Madrid, BAC, II-II, q.8, a.1.
} 
Se trata, en suma, de recuperar "el oficio de pensar que se alimenta de convicciones y se debilita hasta morir si se le nutre de meras convenciones". La persona, al dirigir su voluntad desde la reflexión de su conciencia, se perfecciona y se educa para su libertad. En la medida en que tenga el eco de la conciencia evitará decaer en una libertad negativa, en un libertinaje acelerado. El hombre empieza a ser consciente de sí mismo, a advertirse del mundo y de cómo debe habitar en él, de cómo puede, en últimas, lograr la felicidad. La reflexividad es la raíz de la objetivación. Si la conciencia se distancia del mundo y lo objetiva, es porque su intencionalidad trascendental la hace reflexiva.

El proceso de la objetivación, y de la propia objetivación en el desarrollo de la inteligencia y más aun, de la humanidad y el progreso, es ampliamente descrito por el pensador y antropólogo alemán Arnold Gehlen. ${ }^{28}$ Despertar a la conciencia de su letargo e impedir que tome derroteros materialistas y técnicos en aras de evitar su domesticación inhumana, ha de ser una tarea a la que se debe dar inicio sin más dilación. Formar un hombre integral que se perfeccione en la virtud y se preocupe por el cultivo de su humanidad, a la vez que mejore su cultura y ancle en su ser anhelos de Verdad, de Bien y de Belleza, debe ser un compromiso y una regla que debe liderar a toda acción educativa. Un modelo humanista, que sea reconocible en la medida en que afirma y mejora la condición humana.

El espíritu humano se alimenta y vive de lo esencial: la Verdad, el Bien, la Belleza... Se percibe, así, porque están llamados a fracasar, por su vaciedad, muchos de los métodos y de los proyectos educativos que se proponen ofrecer solución a los graves problemas humanos actuales. Su vacío radica, precisamente, en estar desprovistos, en su base, de una concepción sapiencial acerca de quién es el hombre, quién debería ser y qué necesita para alcanzar su deber-ser. Y es que, como ha advertido Alejandro Llano, "El núcleo de toda cultura es ético y estético; es un ethos que se hace operativo a través de una paideia, es decir, de una formación de la sensibilidad y del carácter que se decanta en un modo de percibir." 29

La educación humanista que aquí se propone exige la presencia de auténticos maestros que posean cierta experiencia en el ejercicio del pensar meditativo. Personas que gracias a su entrenamiento en la reflexión sapiencial, formen a los demás desde esa visión sabia, esto es, unitaria del ser humano y de la vida humana. Maestros que tengan asimiladas y transmitan las verdades

\footnotetext{
28 GEHLEN, Arnold. (1993): Antropología Filosófica, del encuentro y descubrimiento del

hombre por sí mismo. Traducción Carmen Cienfuegos, Paidós, Barcelona, pp. 190-245.

${ }^{29}$ LLANO, Alejandro. (1989): La nueva sensibilidad. Madrid, Espasa-Calpe, p. 57.
} 
fundamentales sobre el ser humano y sobre la realidad en general, verdades que a la vez que ayudan a la comprensión de sí mismo, confieren unidad al saber y, por tanto, a la educación. Formadores que, a semejanza del gran maestro Sócrates, logren persuadirnos de que no nos ocupemos "ni de los cuerpos ni de los bienes antes que del alma ni con tanto afán, a fin de que ésta sea lo mejor posible..." 30

\section{Educar para la libertad: ¿Qué libertad?}

De acuerdo con los postulados antropológicos del humanismo cívico, la educación humanista, al igual que todo lo humano, no puede sino enraizar en una pedagogía de la libertad. Libertad entendida no como pura espontaneidad, sino como liberación de sí mismo. Esta comprensión de la libertad se basa en la restauración del vínculo natural que existe entre ella, la verdad y la ley. En efecto, para entender la libertad como liberación de sí mismo es ineludible asumir que la libertad se esclarece y vigoriza gracias a la verdad y al bien que la preceden.

Ya hemos hecho alguna alusión a que la naturaleza humana es teleológica o normativa: se constituye en norma o medida del obrar humano al sugerirnos cuál es el rumbo que es justo imprimir a cada una de nuestras acciones. De modo que existe una regulación ontológica de la libertad la cual se denomina ley natural. Por ley natural entendemos la ordenación de la naturaleza humana hacia su fin o plenitud racional. Por consiguiente, el contenido de dicha ley lo constituyen los bienes o fines de la naturaleza humana que consisten, ha enseñado Santo Tomás de Aquino, en aquellas cosas a las que el hombre se inclina naturalmente. ${ }^{31}$ Aludir a la ley natural implica, pues, referirse a una ley del ser, en este caso, del ser humano. Ley intrínseca y, por tanto, no impuesta desde fuera, en la que el hombre descubre un horizonte ilimitado para el libre y creativo engrandecimiento de su ser.

A la luz de la verdad metafísica acerca de la naturaleza humana, se puede evidenciar la esencial trabazón existente entre ley y libertad. Porque la libertad humana es la libertad de una criatura y, por lo mismo, sabiamente legislada o "medida" por su Creador; no es, por tanto, anárquica ni absoluta. Y la regla por la cual ha de regirse es ante todo y principalmente, la naturaleza humana y sus

\footnotetext{
${ }^{30}$ PLATÓN. (Trad. 1993): Apología de Sócrates. Madrid, Gredos, 30a-b.

${ }^{31}$ DE AQUINO. (Trad. 1950-1964), I-II, q. 94, a. 2 y a.3. Dichos fines naturales son la conservación del propio ser; la conservación de la propia especie; el bien específico de la naturaleza racional que es el conocimiento de la verdad (también sobre Dios) y el obrar conforme a la razón que equivale a obrar virtuosamente, lo cual implica la tendencia a la vida en sociedad. (Ibidem).
} 
fines inmanentes, o ley natural. Esta ley, porque es manifestación de la profunda verdad sobre el ser humano, no sólo no coarta la libertad, sino que la garantiza y legitima.

En este orden de ideas, es posible distinguir, por un lado, entre la simple libertad psicológica, entendida como la capacidad que tiene la voluntad, orientada por la razón, de autodeterminarse a querer un bien concreto. Y por otro, la libertad emocional o liberación de sí mismo. La primera corresponde a lo que comúnmente se conoce como libre albedrío, que es una propiedad esencial de la naturaleza racional. ${ }^{32}$ Sin embargo, en el ejercicio de dicha libertad psicológica no queda en modo alguno garantizado el que la persona escoja aquellas acciones que verdaderamente la liberan, esto es, opciones que la encaminan hacia la verdad y plenitud de sí misma. Estas opciones son precisamente las que constituyen la libertad emocional o liberación de todo obstáculo que entorpezca el camino hacia la perfección personal. ${ }^{33}$

En consonancia con esto que acabamos de afirmar, es fácil comprender que la libertad no es simple arbitrariedad o pura espontaneidad (o simple capacidad de hacer lo que yo quiero), ausencia de coacción. ${ }^{34}$ Una libertad así entendida implica una seria distorsión de la misma con graves repercusiones en la formación del sujeto. En efecto, cuando la libertad es equiparada a la autonomía subjetiva absoluta, la verdad sobre el ser humano no sólo no antecede al ejercicio de la libertad, sino que desaparece y la verdad se convierte en un resultado de la praxis libre. ${ }^{35}$ Las consecuencias morales negativas que se siguen de esta libertad anárquica son incalculables. El espejismo inicial que prometía "el paraíso" de una libertad sin límites y sin trabas, acaba en la existencia enajenada de un individuo emocionalmente esclavo:

Son los casos, escribe Llano, del alcohólico, del drogadicto, del vanidoso patológico o del play-boy. Cada una de estas personas actúa con pasiones

\footnotetext{
${ }^{32}$ El tema de la libertad psicológica o libre albedrío ha sido desarrollado rigurosamente por Tomás de Aquino; DE AQUINO. (Trad. 1950-1964), I, q.83.

${ }^{33}$ LLANO. (1999): óp., cit, pp.87 y ss.

${ }^{34}$ Esta concepción de libertad es notable desde la promoción de la autonomía desde Descartes y Kant, y muy explícita en las concepciones contemporáneas. Así por ejemplo, en la Teoría Crítica, según la cual "La libertad, en definitiva, será falta de coacción tanto psíquica como física, y lo mismo se puede afirmar de la felicidad y de la justicia". MUÑOZ, Blanca. (2000): Theodor W. Adorno: Teoría crítica y cultura de masas. Madrid, Editorial Fundamentos, p. 258

${ }^{35}$ Paul Ricoeur aclara bellamente cómo la libertad no se puede entender existencialmente sin la inherencia del otro como un tú, y de los otros en plural como institución. En su obra De Sí mismo como del Otro, puede encontrarse un elaborado resumen de esta concepción.
} 
Liliana Irizar - Javier González - Camilo Noguera

compulsivas que prácticamente le obligan a comportarse de una manera autodestructiva, a pesar de no tener ningún obstáculo externo para dejar de comportarse racionalmente; o quizá precisamente por no tenerlo, en una sociedad que muchas veces confunde la libertad con el permisivismo. En un nivel superficial, se puede decir que una persona de este tipo 'hace lo que quiere'; pero eso que, aquí y ahora, quiere impulsada por un placer o un dolor casi irresistibles- no es precisamente lo que ella misma "quisiera querer" (...) Porque lo más significativo de estos casos de emotivismo desbocado es que en ellos se distorsiona la visión de la realidad, se pone como algo esencial aquello que en el mejor de los casos- sólo es accidental, y cada vez resulta más difícil saber cómo son las cosas y quién soy yo. ${ }^{36}$

Para evitar que la libertad se convierta en instrumento de autodisolución de sí misma, se requiere un proceso educativo en el que sujeto aprenda a elevar el nivel ético de sus elecciones personales. Es preciso purificar nuestra libertad en la verdad, habituándola a buscar y a querer el verdadero bien en la vida personal y social. Para conquistar este grado de libertad personal, si bien es necesario, no es suficiente con ejercer acciones libres, es preciso practicar actos liberadores, esto es, acciones por medio de las cuales expansione mi yo "hacia valores que le trascienden y que, a la vez, le afectan y le comprometen".

De ahí que el legítimo anhelo de autonomía, se convierta en desatino cuando se desborda en un afán pedagógico. En la actual educación se insiste con demasiada vehemencia en promover la autonomía. El anhelo de autonomía, tan natural en todas las personas, se pervierte así en un imperativo próximo que, en la falta de experiencia vital del joven, deriva hacia acciones emancipadoras facilistas. Se refuerza el autós, y se debilita rápidamente el nomos. Cuando lo cierto es que la verdadera libertad, la autonomía más profunda y personal, consiste precisamente en ordenar (normalizar o regular) nuestra propia conducta, en liberarnos de nuestras propias ataduras: "el egoísmo está literalmente en la raíz del desequilibrio emocional (...) compete a (la razón y la voluntad) buscar la práctica del amor en cuanto virtud para poner en orden todo el dinamismo de las emociones." ${ }^{37}$

Las presuntamente realistas justificaciones al egoísmo latentes en las distintas ideologías repercuten en una renuncia hacia la propia liberación, centrando el afán emancipador en las estructuras externas, o en las propias

\footnotetext{
${ }^{36}$ LLANO, Alejandro. (2007): Cultura y pasión. Pamplona, EUNSA, p. 53.

${ }^{37}$ DE HOLLANDA CAVALCANTI NETO, Lamartine. (2007): "Contribuiçôes de São Tomás ao estudo das emoçôes", en: Revista Lumen Veritatis, Año 1, №1, p.125; El texto original en português dice: "o egoísmo está literalmente na raíz do desequilibrio emocional (...) compete a estas (razão e vontade) buscar a práctica do amor enquanto virtude para pôr em ordem todo o dinamismo das emoçôes".
}

Rev. hist. edu. latinoam. Vol. 15. Año 2010, pp. 147 - 176 
personas más próximas. Por ejemplo, los maestros. Así, quienes tanto se esfuerzan por convencer a los jóvenes de la necesidad de su propia autonomía, terminan padeciendo los efectos adversos de una educación ideológica centrada en valores e imperativos absolutizados que carecen de la mesura de las virtudes. De hecho, contrario a lo que podría suponerse, esto es aún más cierto en el plano socio-político, donde la prematura emancipación personal incapacita a los jóvenes, demasiado cansados y apáticos, a participar significativamente en el terreno social, resignándose a vivir al margen de los aconteceres públicos, en una privacidad solitaria y desértica, por supuesto, muy fácil de manipular. Así asevera Boladeras que "El ser humano, como sujeto activo del proceso histórico, lleva consigo la capacidad virtual de incidir en él; sin embargo, no cabe esperar ninguna acción emancipadora desde la pérdida de sí mismo." 38

De modo contrapuesto, a la luz del enfoque humanista que propugnamos, la libertad es una libertad capaz de construir sociedad en sociedad, capacitada por la fuerza de sus virtudes, y apta para proyectarse en metas comunes:

No es necesario comprender esta libertad interior como una libertad cerrada; cuanto más la persona humana accede a la libertad espiritual por el conocimiento y la sabiduría, la buena voluntad y el amor, más comprende su solidaridad con las otras personas, y es más apta para participar activamente en la vida social. ${ }^{39}$

La posesión de la verdadera libertad no puede ser el resultado del azar sino que exige un verdadero aprendizaje. Cómo y dónde se lleva a cabo este aprendizaje es el tema que trataremos a continuación.

\section{Enseñar y aprender el arte de vivir}

Quisiéramos dejar planteada como tesis fundamental de este trabajo que la educación humanista ha de caracterizarse como aquella que enseña el arte de vivir. La sociedad actual, mientras ofrece magníficas posibilidades de progreso parece incapaz de proporcionar simultáneamente, las maneras más humanas, sabias, de acceder y hacer uso de dichas posibilidades. Si lo analizamos con

\footnotetext{
38 BOLADERAS, Margarita. (1996): Comunicación, ética y política. Habermas y sus críticos. Madrid, Tecnos, p. 20.

39 ALLARD, Jean-Louis. (1978): L'Éducátion a la liberté ou la philosophie de l'éducátion de Jacques Maritain. Ottawa - Grenoble. Editions de l'Université d'Ottawa, Les presses universitaires de Grenoble. p. 74. El texto original dice: Enfin, il ne faut pas camprender cette liberté intérieure comme une liberté 'close'; plus la personne humaine accède à la liberté spirituelle 'par la connaissance et la sagesse, la bonne volonté et l'amour', plus elle comprend sa solidarité avec les autres personnes, et plus elle est apte à participer activement à la vie sociale.
} 
atención resulta sorprendente, por su desproporción, el adelanto alcanzado en todas las disciplinas científicas y técnicas, por un lado, y por otro lado, el estancamiento, sino el retroceso, respecto del planteamiento riguroso y profundo de cuestiones fundamentales: ¿cómo deberíamos vivir los seres humanos?, ¿cuál es el camino de la felicidad?, ¿cómo se aprende el "arte de vivir”?, ¿qué es la libertad? Podría decirse que en el presente contexto cultural las respuestas a tales preguntas se dan por supuestas. De manera consciente o inconsciente, se asume que cada uno en su fuero privado conoce la respuesta o, al menos, la puede intentar conocer "sobre la marcha."

Sin embargo, resulta llamativo el hecho de que una cultura que exige niveles cada vez mayores de competencia, exactitud y rigor en todos los ámbitos del saber y del hacer humanos, asuma la improvisación como norma justamente en este campo, el del arte de vivir que es el que nos enseña a definir y construir los pilares sobre los cuales se sustenta la entera existencia.

El propósito de este último apartado consiste en presentar la educación humanista como aquella que ofrece al educando unas herramientas conceptuales $\mathrm{y}$ vitales con las cuales se haga apto para afrontar el arduo quehacer de vivir y lo asuma como un aprendizaje sinfín. Un arte que, aunque es absolutamente personal en los modos de asimilarlo, afianzarlo y ejecutarlo, no obstante, posee unas pautas comunes, unas orientaciones de base proyectables sobre toda existencia humana, puesto que radican en la naturaleza teleológica racional.

En este aprendizaje el ser humano es visto como "un ser que no es, de suyo, enteramente perfecto." 40 Por el contrario, se asume como punto de partida que si bien no somos "malos por naturaleza", con todo:

Somos seres auto-perfectibles. Somos autocultivadores de nosotros mismos. Esto significa que, no solamente hay en nosotros el terreno perfeccionable, sino también el principio activo para dicho cultivo. Somos agentes, y no meramente pacientes, de nuestra perfección. Y nuestra capacidad para ser agentes en este campo, radica en el hecho de que poseemos, como algo dado naturalmente, los principios de nuestro propio desarrollo. ${ }^{41}$

El arte de vivir se presenta, así, como el oficio de diseñar y ejecutar el propio proyecto vital. Este modo de ver la educación, mejor aún, la formación, revela la grandeza de la libertad humana que, en la medida de su cultivo y

${ }^{40}$ MILLÁN PUELLES, Antonio. (1963): La formación de la personalidad humana.

Madrid, Rialp, p. 71.

${ }^{41}$ DEWAN. (2008): óp., cit, p. 201.

Rev. hist. edu. latinoam. Vol. 15. Año 2010, pp. 147 - 176 
vigorización por medio de las virtudes, constituye un instrumento poderoso, inquebrantable, capaz de construir la propia vida pasando por encima de la adversidad, material y espiritual, trasponiendo las barreras hostiles impuestas por la propia historia personal o social. Al hablar de autocultivación de la persona, estamos expresando la elevada dignidad del ser humano quien es libre autor del propio carácter, promotor nato del desarrollo de su personalidad. ${ }^{42}$

De acuerdo con esto, el arte de vivir se encuentra en relación directa con la formación de la personalidad humana. Dicha formación se orienta en dos direcciones fundamentales: "el cultivo de la inteligencia y la formación del carácter." ${ }^{43}$ Se trata de un proceso que atiende a la persona en su integridad, es decir, se ocupa del desarrollo tanto de la inteligencia como de la afectividad de manera proporcionada y armónica. Porque para ser capaces de asumir la propia vida como un proyecto se necesita, ante todo, rectitud y claridad de criterio a la hora de fijarse las metas y los modos de alcanzarlas. Pero al mismo tiempo, esos objetivos vitales, para no quedar reducidos a una mera veleidad, exigen contar con las disposiciones estables del carácter denominadas virtudes éticas. Tal como ha escrito MacIntyre, se necesita poseer: "Las cualidades intelectuales y de carácter que permiten a una persona identificar los bienes pertinentes y emplear las habilidades necesarias para conseguirlos..."44

Lo que en esta propuesta educativa se resalta es, por tanto, el "valor de la verdad y del bien como perfección del hombre." ${ }^{45}$ Mientras que la ignorancia y el error nos achatan y esclavizan, allanando, entre otros despotismos, el mediático; la verdad es, de suyo, liberadora. Pero para, en primer lugar, dar con ella y, en un segundo momento, hacerla propia plasmándola en comportamientos concretos de modo coherente, se necesitan las virtudes intelectuales, es decir, hábitos operativos que, como su nombre lo indica, perfeccionan al sujeto en la realización de sus actos de inteligencia, y las virtudes éticas o morales que lo perfeccionan respecto de las actuaciones propias de la vida volitiva y emocional.

Así, gracias a la virtud intelectual o dianoética el entendimiento queda capacitado para decir "(...) siempre la verdad, jamás la falsedad." ${ }^{46}$ En el plano especulativo o teórico, esto se consigue a través de tres virtudes: el intelecto,

\footnotetext{
42 DEWAN. (2008): óp., cit, p. 358.

43 NAVAL, Concepción. (1994): "Sobre la concepción de formación”, en Anuario filosófico. $N^{\circ}$ 27. Pamplona, Universidad de Navarra, p. 615.

${ }^{44}$ MACINTYRE, Alasdaire. (2001): Animales racionales y dependientes. Por qué los seres humanos necesitamos las virtudes. Barcelona, Paidós, p. 110.

${ }^{45}$ LLANO. (1999): óp., cit, p. 197.

${ }^{46}$ DE AQUINO. (Trad. 1954-1960), I-II, q, óp., cit, p. 57, a.3.
} 
la ciencia y la sabiduría ${ }^{47}$ En el campo práctico, es decir, el de la elección y la acción humanas, por medio del arte y la prudencia. ${ }^{48}$ Por razones de brevedad, se resaltarán en este trabajo los dos hábitos intelectuales que más inciden en la formación de una personalidad éticamente madura: la prudencia y la sabiduría.

Por la prudencia se obtiene el discernimiento que permite indagar y juzgar certeramente acerca de las acciones que nos conducen de manera más eficaz a la consecución de una meta buena en caso contrario, se trata no de prudencia, sino de astucia- ; es decir, habilita para conocer cómo realizar y, de hecho, practicar acciones buenas o virtuosas. ${ }^{49}$ De ahí que, la prudencia sólo se da en la medida en que el sujeto se dé al cultivo de las virtudes morales, no se puede ser prudente sin ser virtuoso y, en sentido contrario, enseñará el Estagirita, "... cuando existe la prudencia todas las otras virtudes está presentes." ${ }^{50} \mathrm{Y}$ es que, tal como ha señalado G. Abbá: "Gracias a la influencia de las virtudes, que vuelven atenta, vigilante a la razón práctica in particulari, el sujeto virtuoso interpreta y define su propia situación de un modo distinto del sujeto no virtuoso. Percibe como relevantes circunstancias que de otro modo se le escaparían, elige oportunidades de acción que otros no advierten, considera relevantes normas que otros pasan por alto, se propone fines en los que otros no caen." ${ }^{51}$

La sabiduría, a la que ya se ha hecho alguna referencia, es el ápice de una vida intelectual y moralmente desarrollada. La mirada intelectual sabia aprende a leer, por decirlo así, en la profundidad de las cosas y acontecimientos. Con esta virtud la inteligencia sabe llegar a lo esencial, por eso, es la virtud que confiere unidad a la existencia personal. La unidad que surge de saber juzgarlo todo bajo la luz de su significado último y definitivo. Para esa unidad y simplicidad de visión se necesitan el equilibrio emocional que confieren las virtudes éticas $\mathrm{y}$, por tanto, también poseer la prudencia. ${ }^{52}$

\footnotetext{
47 ARISTÓTELES. (Trad. 1993), VI, Op., cit, p. 7.

48 ARISTÓTELES.(Trad. 1993), VI, Op., cit, p. 4 - 5.

49 «El mérito de la prudencia no consiste solamente en la consideración, sino en la aplicación a la obra, fin del entendimiento práctico.» Tomás de Aquino. (1954-1960), II-II, q.47, a.2, ad.3. considera la sabiduría: pero impera respecto de aquellas cosas que se ordenan a la sabiduría, esto es, de qué modo el hombre debe llegar a ella. De donde, la prudencia, o política, en esto es servidora de la sabiduría: introduce a ella, preparándole el camino, como el portero hacia el rey». Tomás de Aquino. (1954-1960), I-II, q.66, a.5, ad.1.
} 
Por su parte, la virtud ética es un hábito electivo porque «hace buena la elección» ${ }^{53}$. Esto significa que su función consiste en disponer las facultades afectivas (emociones y voluntad) de modo que cooperen positiva y eficazmente en la elección y ejecución de la acción éticamente buena. La virtud moral crea una afición o inclinación permanente hacia el bien racional ${ }^{54}$ al generar una auténtica connaturalización de la facultad apetitiva con dicho bien. Esta sintonía se consigue, por un lado, refrenando y moderando la fuerte atracción que los bienes sensibles suscitan en las emociones. Este trabajo lo realiza la virtud de la templanza. ${ }^{55}$ Por otro lado, el equilibrio emocional consiste también en fortalecer nuestra afectividad para que no claudique, sino que se mantenga firme y constante en su esfuerzo por superar todo tipo de obstáculos, lo cual es tarea de la fortaleza. ${ }^{56}$ Por su parte, la justicia es la virtud que rectifica a la voluntad haciéndola idónea para querer efectivamente "lo debido a otro." ${ }^{7}$

Según lo dicho hasta aquí, se advierte que la liberación de sí mismo es decir, de las propias tendencias egoístas- da lugar a una ganancia antropológica decisiva: el llegar a ser, como ha señalado MacIntyre, razonadores prácticos independientes. Esto es, sujetos capaces de evaluar las razones para actuar de los demás, así como para dar razón y respaldar nuestras propias acciones. ${ }^{58}$ El aprendizaje virtuoso que todo ese proceso auto-educativo supone arroja como resultado un sujeto cuyo equilibrio emocional garantiza la imparcialidad, unidad y firmeza de criterio a la hora de evaluar las propias acciones y de hacer juicios prácticos efectivos. La virtud, anota MacIntyre, produce ese efecto hondamente liberador que implica el ser apto para tomar distancia de los propios deseos y juzgarlos como lo haría un observador externo. No se trata, por tanto, de erradicar de la propia vida los deseos y emociones, sino de encauzarlos integrándolos en la unidad de una vida lograda o vida buena. ${ }^{59}$

\footnotetext{
${ }^{53}$ DE AQUINO. (1954-1960), I-II, q.58, a.4, Op., cit.

${ }^{54}$ DE AQUINO, Tomás. (Trad. 1997): De las Virtudes. Santiago-Chile, Universidad de los Andes, q. única, a.9.

55 DE AQUINO. (1954-1960), II-II, q. 141, a.3: “(...) la templanza -que es moderadora de los movimientos inferiores- se fija preferentemente en las pasiones que tienden al bien sensible, a saber, los deseos y placeres..."

${ }^{56}$ DE AQUINO. (1954-1960), II-II, q.123, a.1: «Ahora bien, existe una doble clase de obstáculos que impiden a la voluntad humana someterse a la rectitud de la razón (...) El segundo es el que repele a la voluntad del orden de la razón por la inminencia de algo difícil. Para quitar este obstáculo es precisa la fortaleza, la cual debe hacer frente a tales dificultades, al modo como, por medio de la fuerza corporal el hombre supera y rechaza los obstáculos corporales.»

${ }^{57}$ DE AQUINO. (1954-1960), I-II, q.56, a.6.

${ }^{58}$ MACINTYRE. (2001): Op., cit. p. 126.

${ }^{59}$ SPAEMANN, Robert. (2007). Ética política y cristianismo, trad. J. M. Barrio y R. Barrio. Madrid, Ediciones Palabra, p. 142.
} 
Así, los hábitos antropológicos dilatan las fuerzas del alma porque amplían en "anchura y profundidad" la personal percepción de lo real, porque, tal como hace notar Aristóteles: "El hombre bueno, en efecto, juzga bien todas las cosas, y en todas ellas se le muestra la verdad". ${ }^{60}$ El sujeto virtuoso conquista para sí una sabiduría práctica o prudencia que lo habilita para dar lúcida y eficazmente con aquello que ansía nuestro ser más profundo: todo lo verdadero, bueno y bello por lo que, en definitiva, vale la pena decidirse y vivir. En este sentido, observa Millán Puelles, que la posesión de las virtudes éticas y, consiguientemente, de la prudencia, "hace posible al hombre la recta autonomía de su conducta: aquella emancipación por la que llega a regir por sí su propia vida, y merced a la cual se encuentra en condiciones de hacerse íntegramente responsable de ella. Todo esto guarda una profunda conexión con la idea pedagógica de la madurez moral..." 61

\section{CONCLUSIONES}

\section{Formar centros en la periferia: aprender a pensar y vivir desde la amistad}

El ser humano, como ser constitutivamente racional, es un ser que busca cimentar todas sus acciones en la verdad de los hechos, y especialmente, en el sentido mismo de la realidad. Por ello, toda educación humana es de alguna manera teórica, y toda educación teórica es relevante en toda la vida y el existir de la persona. La educación teórica previene y evita los peligros del conductismo y alivia de los temores del sinsentido. La teoría, así vista, no es la construcción quimérica de unas voces vacías entretejidas, sino la asimilación reflexiva de los seres del mundo, sus formas de ser y sus relaciones. El fin de este tipo de teoría es la verdad, y a este fin, y a esta teoría, toda persona tiende por naturaleza llegar.

Pero dicha tendencia natural es de difícil consecución y exige inexcusablemente la ayuda y colaboración mutuas. Es en relación con los demás como se alcanzan los mayores logros humanos, y se conquistan los más altos valores, "Sólo en este tejido de relaciones interpersonales logra el hombre conquistar una personalidad (en el sentido de perfección personal)" 62

La naturaleza de la educación en virtudes que proponemos como la mejor forma de educar para el desarrollo social, afirma la preeminencia de las comunidades de amistad como ámbito privilegiado para la educación moral y el

\footnotetext{
${ }^{60}$ ARISTÓTELES. (Trad. 1993), III, 4, 1113a25-30, Op., cit.

${ }^{61}$ MILlÁN PUELLES, Antonio. Op., cit. p. 86.

${ }^{62}$ FERRER ARELLANO, Joaquín. (1998): Metafísica de la relación y de la alteridad.

Persona y relación. Pamplona, EUNSA, p. 34.
} 
desarrollo ético, así como para el arraigo de las convicciones religiosas más profundas, con primacía sobre los agentes institucionales del sistema educativo. Claro que la denominada educación "integral" de las instituciones educativas primarias, secundarias y superiores, junto con educación para la ciudadanía de parte de sectores públicos y voluntariados sociales, pueden estimular y complementar la formación personal, pero no la pueden suplir. De hecho, se deben promover este tipo de "subsidios" formativos de parte de otros agentes como lo son las instituciones educativas y el estado. Lo cual, por demás, se debe suscitar activamente, y dicha promoción debe consistir, efectivamente, en fomentar el papel insustituible de la familia como sustento primario de la madurez y del equilibrio afectivo de la persona. En segundo lugar, ese papel lo desempeñan las demás comunidades de amistad, de modo particular las que se generan al abrigo de los docentes tanto en el colegio como en la universidad.

Conviene tener presente que las comunidades de amistad solamente se hacen comprensibles a la luz del paradigma ético de la comunidad aristotélica la cual implica la vital necesidad de la concordia entre los diversos pareceres y elecciones individuales, tratando de armonizarlos con los "intereses de la ciudad" que en último término han de converger siempre en el bien común de la vida buena. Este acuerdo vital de mente y corazón entre los ciudadanos acerca de lo que es justo y conveniente para la ciudad se conoce en la filosofía de inspiración clásica como amistad cívica o amistad política ${ }^{63}$ También puede denominarse amistad social. Este tipo de amistad no llega a ser una amistad personal de plena donación y concordancia, pero es, sin embargo, amistad en tanto que se da en ella la benevolencia recíproca, condición básica de todo tipo de amistad. ${ }^{64}$ En este caso, el bien que cada uno de los ciudadanos quiere recíprocamente, es algo de utilidad o de interés para todos (como por ejemplo, el acuerdo sobre lo que es justo en una cuestión determinada o sobre el tipo de gobierno que los debe regir). ${ }^{65}$ Ello podría parangonarse con la perspectiva de Paul Ricoeur, para quien si bien en el ámbito público de las instituciones y de la sociedad no se puede dar la amistad tal como se da a nivel personal, con todo, reconoce que sí hay una continuidad de este tipo de amistad en el ámbito social, que es identificable con el reconocimiento comunitario de lo justo. ${ }^{66}$

Este singular modo de amistad, cimentado como está sobre la recíproca benevolencia entre los ciudadanos, benevolencia que equivale en este caso a

\footnotetext{
${ }^{63}$ ARISTÓTELES. (Trad. 1993): IX, 6, 1167 a20-1167 b15.

${ }^{64}$ ARISTÓTELES. (Trad. 1993): VIII, 3, 1156 a5-10.

${ }^{65}$ ARISTÓTELES. (Trad. 1985): Ética Eudemia. Madrid, Gredos, VIII, 10.

${ }^{66}$ RICOEUR, Paul. (trad. 1996): Sí mismo como otro, trad. A. Neira y M. C. Alas de

Tolivar. México, Siglo Veintiuno Editores.
} 
querer el bien de todos o bien común, se estrena y vigoriza en esos dos ámbitos primarios de solidaridad constituidos por la familia, la escuela, y posteriormente, la universidad. Las dos primeras representan lo que podemos denominar comunidades de amistad básicas porque en ellas, debido a su limitada dimensión y a su relativa homogeneidad de intereses, es hasta cierto punto fácil iniciarse en la experiencia del compromiso serio y generoso con $l o$ común. Por lo demás, la amistad es sin duda la más sincera forma de reconocimiento del otro. Hoy en día, que tanto se aboga e inquiere por el reconocimiento del otro en medio de la identidad y la diferencia, ${ }^{67}$ muchas veces se desdibuja el sentido mismo del otro, es decir, de aquél que debe ser objeto de mi reconocimiento. De modo que, el discurso del reconocimiento suele perderse en un reconocimiento mera y abstractamente lingüístico, cuando no reducidamente político, jurídico, estructural. Es así que, dentro del tipo de relación interpersonal constituido por la amistad, que el reconocimiento del otro, con sus diferencias, se hace pleno y efectivo, pues el otro es reconocido como otro en tanto que persona. Es decir, en tanto que digno en su humanidad y relevante en su singularidad.

Con relación al tema que nos ocupa, queremos destacar que dentro de las comunidades de amistad, la escuela y la universidad se caracterizan por ser, en primer lugar, comunidades de pensamiento. Y la historia de la educación demuestra que ésta florece allí donde el suelo tiene la fertilidad de las comunidades de pensamiento. El mismo sentido de los términos gimnasio, liceo, colegio, universidad y academia, está históricamente comprometido con la presencia de auténticas comunidades de pensamiento. Tal vez sea precisamente esto, lo que más nos falte en Latinoamérica, porque, tal como ha señalado Alejandro Llano:

Nada puede sustituir al encuentro interpersonal que acontece entre profesores, estudiantes y todos los que trabajan en la Universidad. Cuando se produce, en el aula, en el laboratorio, en un despacho, en un pasillo o al aire libre del campus, la palabra se hace cauce de unas personalidades que se abren a otras para actualizar el servicio conjunto a la verdad, el bien y la belleza. La Universidad no es una factoría de informaciones brutas que pasan de mano y mano. Su personal no está compuesto por las 'terminales humanas' de unas redes informáticas que todo lo supieran, cuando en rigor ellas mismas no saben nada. La Universidad es una ámbito privilegiado de eso que los clásicos llaman 'amistad social'. ${ }^{68}$

\footnotetext{
${ }^{67}$ AAVV. (2010): Reconocimiento y diferencia. Idealismo alemán y hermenéutica: un retorno a las fuentes del debate contemporáneo. Bogotá, Universidad de los Andes - Siglo del Hombre Editores.

${ }^{68}$ LLANO. (2003): óp., cit, pp.89-90.
}

Rev. hist. edu. latinoam. Vol. 15. Año 2010, pp. 147 - 176 
La mejor manera en la que los maestros y las instituciones de educación, de todos los niveles del sistema educativo, pueden estimular en los educandos dichas comunidades de pensamiento, es abandonando las desafortunadas prácticas de desconfianza mutua (intermaestros, interinstituciones, o entre la institución y los maestros). Debe disminuir la mezquindad de las instituciones, y aumentar el compromiso de los maestros. Los docentes no se pueden reunir únicamente a criticar a sus estudiantes o a discutir planes sociales, económicos o políticos. Las salas de profesores deberían estar mucho más dedicadas al pensamiento, la confianza y la mutua ayuda, generando auténtica academia. Este es un ejercicio que, lejos de ser "utópico", puede ser realizado por cada maestro. No puede ser reemplazado por convivencias frívolas o emotivas con los estudiantes, pues lo que en dichos espacios logre hacerse sería borrado con la fuerza del mal ejemplo. Los estudiantes, jóvenes y mayores, requieren menos convivencias y más ejemplo, de parte de sus tutores.

Aunque no se puede olvidar nunca que la última palabra en lo concerniente a la educación auténtica, de la cual depende el auténtico desarrollo, le pertenece a la libertad personal de cada quien. Un libertad cultivada en el ejercicio teóricopráctico del arte de vivir. Un arte que se aprende, sin embargo, también con la palabra, pero que necesita definitivamente del ejemplo, el cual brota en abundancia en las comunidades de amistad.

La eficacia pedagógica de la comunidad de pensamiento no reposa sobre la simple proximidad generacional, ni sobre una estrategia organizativa, ni por parentesco del lenguaje, sino por la fuerza liberadora de la amistad y las relaciones personales de confianza. Es decir, el fomento de la comunidad que proponemos no se reduce a ser un recurso de eficacia, aunque tampoco niega el valor de utilizar la proximidad de la edad y del lenguaje como medios pedagógicos, y del grupo como una forma más eficiente de administrar la educación. Lo que se propone es fomentar las relaciones personales significativas, como la única forma de arraigar convicciones éticas y valores cognoscitivos relevantes para los educandos, lo suficientemente firmes y duraderos como para repercutir por el resto de la vida, y como para repercutir en la sociedad; y se propone que algunas de dichas relaciones profundamente personales surjan del mutuo cuestionamiento a cerca de la verdad.

Estas relaciones significativas se dan primordialmente en la familia, lo cual es algo relativamente bastante sabido. Pero este tipo de relaciones se pueden dar también en el seno de la amistad, y esto es algo que está más al alcance de los educadores. 
El fomento de la amistad es un factor protector ${ }^{69}$ que estimula y refuerza los círculos de confianza llamados a contrarrestar el efecto perverso y altamente antisocial de la sospecha. Ahora bien, este propósito no se puede reducir a un recurso metodológico, porque educar no es principalmente una estrategia o una prescriptiva metodológica. Pese a lo que el cientificismo de opinión pública quiere imponer, el método no es el garante último de la verdad, ni su sustitutivo útil. No es el criterio fundamental, ni la solución práctica a los problemas morales. El método no puede ocupar el lugar de la honestidad intelectual, que requiere más humildad que especificidad técnica. El método, una vez adquirido su lenguaje técnico, sólo exige estar someramente "actualizado". En cambio, la honestidad intelectual y la coherencia vital son la para la vida, por eso piden esfuerzo y compromiso permanente con la profesión y la cultura. Esto es especialmente válido para el maestro.

Las comunidades de pensamiento se caracterizan porque, en medio de búsqueda del sentido y la verdad, surgen relaciones de mutua confianza. Relaciones en las que las prácticas de cuidado, atención, perdón, solidaridad, cumplimiento, responsabilidad, donación, respeto, humildad y magnanimidad, se suceden corrientemente bajo la férula de las promesas compartidas con las que todos se sienten identificados y comprometidos, promesas ${ }^{70}$ direccionadas al acompañarse en el conocimiento. Prácticas que, a su vez, facilitan enormemente el trabajo académico e intelectual, en suma la consecución de la verdad en las distintas áreas del conocimiento. En las comunidades de pensamiento las metodologías van y vienen, pasan. Inclusive las preguntas y respuestas se suceden casi accidentalmente. En cambio, las personas transitan por ellas sintiéndose valoradas por su propio nombre, y heredando un legado personal irremplazable y altamente estimable que las hace reverenciar piedad hacia su alma mater.

En suma, nuestra propuesta de una educación humanista para Latinoamérica, se cifra en un apostar por la persona y su formación verdadera que conduce, casi infaliblemente, al verdadero desarrollo. Una propuesta a favor de lo esencial, lo cual, si bien no es siempre fuente de utilidad, es, sin embargo, germen seguro de fecundidad. ${ }^{71}$

\footnotetext{
${ }^{69}$ MACHUCA ROJAS, JOSÉ RAÚL. (2002): Resiliencia: Una aproximación a la capacidad humana para afrontar la adversidad. Serie Diálogos. Universidad Nacional de Colombia, pp. 58- 136.

${ }^{70}$ Sobre la profundidad de la categoría relacional de la promesa, Cfr. SPEAMANN, Robert (2000): Personas. Acerca de la distinción entre 'algo' y 'alguien'. Trad. Ed. José Luís del Barco, Pamplona, EUNSA, pp. 213- 225.

71 "Y es que la apuesta incondicional por la eficacia genera una espantosa esterilidad. La apuesta por la fecundidad, en cambio, presupone un suelo fértil, una cultura, un cuidado, un cultivo del espíritu." LLANO, Alejandro. (2003): óp., cit, p. 119.
} 


\section{FUENTES}

REPÚBLICA DE COLOMBIA, Ley 790 de 2002.

\section{REFERENCIAS}

AAVV. (2010): Reconocimiento y diferencia. Idealismo alemán y hermenéutica: un retorno a las fuentes del debate contemporáneo. Ed. María del Rosario Acosta. Bogotá, Universidad de los Andes, Siglo del Hombre Editores.

ABBÀ, Giuseppe. (1992): Felicidad, vida buena y virtud. Barcelona, EIUNSA.

ALLARD, Jean-Louis. (1978): L'Éducàtion a la liberté ô̂ la philosophie de l'éducàtion de Jacques Maritain. Ottawa - Grenoble. Editions de l'Université d'Ottawa, Les presses universitaires de Grenoble.

DE AQUINO, Tomás. (2001): El ente y la esencia, en Opúsculos y cuestiones selectas. Madrid, BAC.

DE AQUINO, Tomás. (Trad. 1950-1964): Suma teológica. Madrid, BAC.

DE AQUINO, Tomás. (Trad. 1997): De las Virtudes. Santiago-Chile, Universidad de los Andes.

DE HOLLANDACAVALCANTI NETO, Lamartine. (2007): “Contribuiçôes de São Tomás ao estudo das emoçôes", en: Revista Lumen Veritatis. № 1. Sao Paûlo.

ARISTÓTELES. (Trad. 1993): Ética Nicomaquea. Madrid, Gredos.

ARISTÓTELES. (Trad. 1994): Metafísica. Madrid, Gredos.

ARISTÓTELES. (Trad. 1995): Física. Madrid, Gredos.

ARISTÓTELES. (Trad. 1985): Ética Eudemia. Madrid, Gredos.

ARISTÓTELES. (Trad. 1978): Acerca del alma. Gredos.

BOLADERAS, Margarita. (1996): Comunicación, ética y política. Habermas y sus críticos. Madrid, Tecnos.

DEWAN, Lawrence, O.P. (2008): Wisdom, Law and Virtue, Essays in Thomistic Ethics. New York, Fordham University Press.

FERRER ARELLANO, Joaquín. (1998): Metafísica de la relación y de la alteridad. Persona y relación. Pamplona, EUNSA. 
Liliana Irizar - Javier González - Camilo Noguera

GEHLEN, Arnold. (1993): Antropología Filosófica, del encuentro y descubrimiento del hombre por sí mismo. Traducción Carmen Cienfuegos. Paidós, Barcelona.

GONZÁLEZ GONZÁLEZ, Ana Marta. (1999): Naturaleza y dignidad. Un estudio desde Robert Spaemann. Pamplona, EUNSA.

IRIZAR, Liliana. (2006): Preámbulos de la esperanza. Reflexiones en torno al humanismo cívico de Alejandro Llano. Bogotá, Fondo de Publicaciones de la Universidad Sergio Arboleda.

LLANO, Alejandro. (2007): Cultura y pasión. Pamplona, EUNSA.

LLANO, Alejandro. (1985): El futuro de la libertad. Pamplona, EUNSA.

LLANO, Alejandro. (2003): Repensar la universidad. Madrid, EUNSA.

LLANO, Alejandro. (1999): Humanismo cívico. Barcelona, Ariel.

LLANO, Alejandro. (1989): La nueva sensibilidad. Madrid, Espasa-Calpe.

MACHUCA ROJAS, José Raúl. (2002): Resiliencia: Una aproximación a la capacidad humana para afrontar la adversidad. Serie Diálogos, Universidad Nacional de Colombia.

MACINTYRE, Alasdaire. (2001): Animales racionales y dependientes. Por qué los seres humanos necesitamos las virtudes. Barcelona, Paidós.

MACINTYRE, Alasdair. (1999): Tras la virtud. Trad. A. Valcárcel. Barcelona, Editorial Crítica.

MEMORIAS. (1998): Políticas y Estrategias para la transformación de la Educación Superior en América Latina y el Caribe. Bogotá, UNESCO. ASCUN.

MILLÁN PUELLES, Antonio. (1963, 1989): La formación de la personalidad humana. Madrid, Rialp.

MUÑOZ, Luis Carlos. (1998): Discurso de instalación, en Políticas y Estrategias para la transformación de la Educación Superior en América Latina y el Caribe. Bogotá, UNESCO, ASCUN.

MUÑOZ, Blanca. (2000): Theodor W. Adorno: Teoría crítica y cultura de masas. Madrid, Editorial Fundamentos.

NAVAL, Concepción. (1994): Sobre la concepción de formación, en Anuario filosófico. $N^{\circ}$ 27. Pamplona, Universidad de Navarra.

ORTEGA Y GASSET, José. (2002): Misión de la Universidad. Madrid, Alianza. 
PLATÓN. (Trad. 1993): Apología de Sócrates. Madrid, Gredos.

RAMÍREZ, Luis Alfonso. (1998): Discurso de instalación, en Políticas y Estrategias para la transformación de la Educación Superior en América Latina y el Caribe. Bogotá, UNESCO, ASCUN.

RICOEUR, Paul. (1996): De Símismo como del Otro. México. Siglo XXI Editores S.A. SPAEMANN, Robert. (2007): Ética política y cristianismo. Madrid, Ediciones Palabra. SPEAMANN, Robert (2000): Personas. Acerca de la distinción entre 'algo' y 'alguien'. Pamplona, EUNSA.

SPAEMANN, Robert. (1994): Ensayos filosóficos. Madrid, Ediciones Cristiandad.

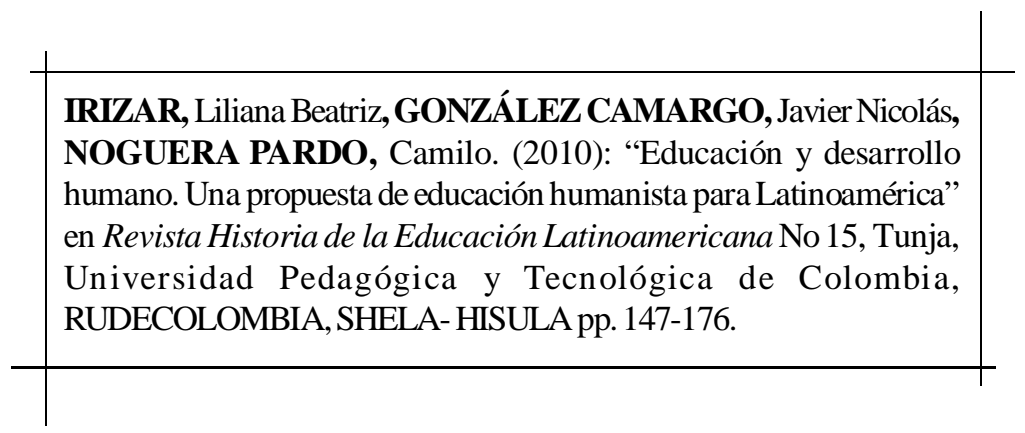

Rev. hist. edu. latinoam. Vol. 15. Año 2010, pp. 147 - 176 